\title{
The changing nature of our food systems
}

\author{
The wealth of national food supply data, collected over decades by member states of the Food and Agriculture \\ Organization, provides intriguing insights into regional transitions.
}

\section{Roseline Remans}

\begin{abstract}
$\mathrm{n}$ history class, teachers do not talk much about food. And while there are fascinating books that tell the history of individual food items, it has been difficult to grasp to what extent food supply, as a whole, changes when societies and ecosystems go through major transitions. Using an innovative data-driven approach, Bentham et al. ${ }^{1}$ in this issue of Nature Food constructed an index that captures exactly that - the extent of changes in global food supply over time. Using data from 171 countries over a period of 50 years, the researchers provide captivating insights on the dynamics of our food systems, and trigger new questions on how changes in food supply relate to other changes in our societies and environment.
\end{abstract}

Over the last 50 years the largest change in food supply globally has been in East Asia, particularly China, Taiwan and South Korea. Rapid economic growth, urbanization, industrialization and a supermarket revolution ${ }^{2}$ in the region has been reflected by increases in the supply of meat and sugar, seafood and oil crops, and vegetables - the latter of which, in general, we still eat too little of worldwide ${ }^{3}$. While it is not new that these particular food groups increase in supply as societies grow richer $^{4}$, it is remarkable that, with fruits and starchy roots, they account for nearly $90 \%$ of variation in food supply across countries, despite only providing around $30 \%$ of our calories $^{5}$. A large bulk of the food supply consists of major cereals, such as maize, wheat and rice (cereals as a single food group already provide more than $40 \%$ of our calories ${ }^{5}$ ), but those have become so dominant around the world that they do not explain much of the differences between countries.

Each country and population group has its own trajectory of change in food supply, but there are also many global interlinkages. Western diets are influencing Asian diets, which are moving towards more meat consumption, and Asian diets are inspiring Western diets to include more vegetables. The paper hints at those crosspollinations and cross-sectoral linkages but triggers more curiosity and more questions, such as how rapid change in food supply influences food system sustainability; what the various stories and pathways of change are; how changes in national food supply are driven and experienced by different groups of the population (rural versus urban, poor versus wealthy); and to what extent food production systems have changed in parallel. This first application of a change index to food supply ${ }^{1}$ is limited in addressing such questions. But the methodology is flexible and can be applied to any temporal dataset (under the condition that there are sufficient data points). With the industrialization of our food systems, it will be critical to consider the effects of food processing in changes to food supply. Food processing can drastically alter the nutritional characteristics of our food, as well as the convenience of use, storage, transport, environmental footprint and more. Capturing the extent to which food processing changes our food supply will enable us to make better connections between health and the environment.

Food system literature is a rapidly growing field, with contributions across many disciplines. The particular value of this study is that it focuses on, and allows capture of, the dynamic nature of food systems. Our food systems are continuously changing, and we need to move beyond taking snapshots in time. Those dynamics matter for farmers and consumers, and cut across disciplines. They may also inspire teachers to give a more prominent place for food in our history classes.

\section{Roseline Remans (ID}

The Alliance of Bioversity International and the International Center for Tropical Agriculture (CIAT), CGIAR, Rome, Italy.

e-mail:r.remans@cgiar.org

Published online: 13 January 2020

https://doi.org/10.1038/s43016-019-0015-z

References

1. Bentham, J. et al. Nat. Food https://doi.org/10.1038/s43016-0190012-2 (2020).

2. Reardon, T., Timmer, C. P. \& Minten, B. Proc. Natl Acad. Sci. USA 109, 12332-12337 (2013).

3. Willett, W., Rockström, J. \& Loken, B. Lancet 393, 447-492 (2019).

4. Bonhommeau, S. et al. Proc. Natl Acad. Sci. USA 110, 20617-20620 (2013).

5. Food Balance Sheets (FAOSTAT, accessed 1 December 2019); http://www.fao.org/faostat/en/\#data/FBS

6. Béné, C. et al. Sci. Data 6, 279 (2019).

Competing interests

The author declares no competing interests. 